\title{
EN BUSCA DE LA GRAN TRANSICION
}

Redes de parentesco y normas para la aceptación de matrimonios en torno a la prohibición del incesto son universales en las sociedades de cazadores-recolectores actuales. Sugiero que las redes de parentesco ya existían en poblaciones humanas hace unos 200 ka en el sur de África.

\section{Osvaldo Nestor Herrera}

Investigador independente

e-mail: onherrera@protonmail.com

RESUMEN - De acuerdo a Lévi-Strauss, todas las sociedades de cazadores-recolectores conocidas históricamente conformaron redes de relaciones de parentesco y normas para la aceptación de los matrimonios alrededor de la prohibición del incesto, que limita el número de uniones matrimoniales posibles favoreciendo un sistema más extenso de vínculos. Reviso un estudio etnográfico, realizado por la familia Marshall con cazadores-recolectores Ju/’hoansi, para reconocer los vínculos que se establecen entre relaciones de parentesco y supervivencia. Reviso resultados recientes de estudios paleoantropológicos que pueden informarnos acerca del surgimiento de estos nuevos modos de vida. Sugiero que relaciones de parentesco y normas para la conformación de matrimonios, con redes de relaciones de reciprocidad extensas que favorecen la supervivencia, ya existían en poblaciones humanas 200 ka atrás en el sur de África.

PALABRAS CLAVE - Relaciones de parentesco, Prohibición del incesto.

\section{INTRODUCCION}

El antropólogo francés Claude Lévi-Strauss (Kuper 2009) publicó en 1949 uno de sus textos más importantes: Les structures élémentaires de la parenté, que presentó como una introducción a una teoría general de sistemas de parentesco, basada en información etnográfica disponible principalmente en la primera mitad del siglo veinte.

De acuerdo a Claude Lévi-Strauss, todas las sociedades de cazadores-recolectores conocidas históricamente conformaron redes de relaciones de parentesco y normas para la aceptación de los matrimonios alrededor de la prohibición del incesto. La prohibición del incesto, como norma universal, es la respuesta a la universalidad de los instintos: hay prohibición porque hay deseo. La prohibición sólo puede ser posible si existen capacidades cognitivas que incluyan proyectar futuros posibles y controlar deseos presentes, que son exclusivamente humanas. La prohibición del incesto limita el número de uniones matrimoniales posibles favoreciendo un sistema más extenso de vínculos y de alianzas. En resumen: 
«Considered from the most general viewpoint, the incest prohibition expresses the transition from the natural fact of consanguinity to the cultural fact of alliance»

(Lévi-Strauss 1969 [1949]: 30)

Si esta «transition from the natural fact of consanguinity to the cultural fact of alliance» indica un proceso pasado, nadie ha propuesto aún, de acuerdo a mi conocimiento, cuando ocurrió. El objetivo de este trabajo es presentar una teoría que de cuenta del surgimiento de las relaciones de parentesco y de las normas para la formación de matrimonios, sugiriendo su cronología.

\section{EXPLORANDO EVIDENCIAS}

Se pueden explorar tres partes principales de la expresión de Lévi-Strauss recién citada, que permiten construir una teoría sobre el surgimiento de las relaciones de parentesco y las normas para la formación de los matrimonios: (I) «the cultural fact of alliance» (II) «the incest prohibition» y (III) «the transition».

\section{(I) Información etnográfica y «the cultural fact of alliance»}

Los cazadores-recolectores Ju/'hoansi sumaban alrededor de mil personas durante los años 50, preservando una forma de vida tradicional en el área de Nyae-Nyae (Namibia) y en el área de Dobe (Botswana), ambas conformando una región del Kalahari en el sur de África, una de las partes más aisladas de la sabana árida en el sur de África durante el siglo XX. Los ju/’hoansi hablan un dialecto !Kung, por lo que en las publicaciones de los años 50 a 70 se los denominaba con este nombre.

La familia Marshall inició en 1950 una serie de ocho campañas hasta 1961 en el área de Nyae-Nyae, para un estudio etnográfico con grupos nómadas de cazadores-recolectores Ju/’hoansi (Marshall 1976). Richard Lee e Irven DeVore iniciaron en 1963 otro estudio etnográfico con cazadores-recolectores ju/'hoansi en el área de Dobe, enfocándose en gran medida en temas ecológicos (Lee 1976).

Las familias ju/'hoansi se juntan sobre la base de la consanguinidad y la afinidad. Una de estas relaciones vincula a cada individuo con una familia, cada familia con otra familia en una banda (n/ / abesi), la unidad en la que las familias se combinan para vivir juntas en grupos de tamaño viable. Un Ju/'hoan habla de su territorio (n!ore), como el lugar en el que vive o al que pertenece (Marshall 1976).

La interacción de la población Ju/'hoan como un todo en la región se rige por un patrón de parentesco. Este patrón se basa y se extiende a partir de los numerosos lazos de parentesco reales. Los matrimonios mixtos dentro de la región han unido a las personas a través de bandas (Marshall 1976).

Los Ju/'hoansi visitan a familiares y amigos. Visitan por muchas razones, por el placer de ver a las personas con las que les gusta estar, para cambiar de aire, para dar y recibir regalos, para arreglar matrimonios, para recibir noticias de matrimonios, nacimientos y defunciones, y para participar en rituales (Marshall 1976).

La sociedad ju/'hoan, rigurosamente y sin excepción, exige que todos los hombres vayan a vivir con los padres de sus novias y les presten un servicio. La duración del servicio es indefinida, pero la gente dice que 
debería ser suficientemente extenso como para que nazcan tres hijos (Marshall 1976).

El servicio que da un hombre es la caza. Un hombre es responsable del sustento de sus padres y sus dependientes, y cuando se casa, también es responsable del sustento de los padres de su esposa y sus dependientes. Si pasa de una banda a otra para dar servicio, lleva consigo a los que necesitan o quieren acompañarlo. El servicio mueve segmentos completos de bandas para unirse a otras bandas (Marshall 1976). El principal tiempo de los cazadores ju/'hoansi esta dedicado a la búsqueda de animales grandes. Los grandes antílopes, porque pasan largos períodos sin beber, no acuden regularmente a los pozos de agua, vagan por cualquier parte del terreno, están muy dispersos, solos o en manadas de pocos animales. Cuando los cazadores encuentran el rastro de grandes animales, lo siguen. Los grandes antílopes son cazados regularmente con flechas envenenadas. La costumbre de compartir la carne se aplica a los grandes animales que son cazados deliberadamente por partidas de caza y el resultado es que todos obtienen algo de carne, estableciendo una obligación mutua (Marshall 1976).

El dueño del animal es el dueño de la primera flecha que se dispara efectivamente al animal y que penetra lo suficiente como para que su veneno funcione. Esa persona es responsable de la distribución. Puede haber varios cazadores en el grupo de caza y varias flechas en el animal, pero esto parece no causar confusión ni conflicto. Se conoce cada flecha y los cazadores pueden ver cuál penetró primero y de manera efectiva para que su veneno pueda ser responsable de la muerte. De todos modos, cada cazador obtiene una parte de la carne (Marshall 1976).

La primera distribución que hace el dueño es a los cazadores y al dador de la flecha, si la flecha no fue hecha por él mismo. La carne, siempre cruda en la primera distribución, se da con hueso a menos que el animal sea tan grande que la carne haya sido cortada en tiras en el momento de trozar al animal (Marshall 1976).

En una segunda distribución, las personas que obtuvieron carne en la primera distribución, a su vez la distribuyen. Esta carne también se da cruda. La primera obligación de un hombre es dar a los padres de su esposa. Debe darles lo mejor que tiene en porciones tan generosas como pueda, mientras cumple con otras obligaciones primarias, que son para con sus propios padres, su cónyuge y su descendencia (Marshall 1976). Todo el que recibe carne vuelve a dar, en otra ola de compartir, a sus padres, suegros, cónyuge, hijos, hermanos y otros. La carne se puede cocinar y las cantidades pueden ser pequeñas. El resultado de esta última distribución es que todos obtienen algo de carne (Marshall 1976).

Los Ju/'hoansi son conscientes del valor de compartir la carne y hablan de ello, especialmente del beneficio de la obligación mutua que conlleva, y la idea de compartir la carne obtenida a través de la caza está muy arraigada (Marshall 1976).

En el Kalahari, debe haber un pozo de agua permanente o semipermanente cerca del cual se asiente la banda que habita el territorio en la estación seca. Un estilo de vida centrado en sostener lazos pacíficos les permitió compartir pozo de agua entre varias bandas, durante una estación extremadamente seca:

«!Kung bands have an entity that is visible to the eye. When the band encamps, the members cluster their fires together. If more than one band inhabits a territory and 
the bands encamp near the same waterhole, or if bands are visiting and are encamped near their hosts, the bands maintain a distinct separation. We had an unusually good opportunity to observe this particular characteristic during the drought of 1952 when five bands encamped themselves around the /Gam waterhole.»

(Marshall 1976: 179)

Los comportamientos que caracterizan a los grupos ju/'hoansi, con relaciones familiares extensas y redes de relaciones recíprocas, se expresan en espacios sociales amplios pero bien definidos, favoreciendo la supervivencia grupal incluso en escenarios desfavorables. La pertenencia a un territorio y la existencia de vínculos sociales firmes con los grupos que habitan en el entorno, se ensamblan, lo que les permite permanecer y sobrevivir por largos períodos de tiempo en un lugar, incluso en condiciones desfavorables. Las familias ju/'hoansi conservan actualmente la mayor diversidad genética nuclear entre todas las poblaciones humanas, lo que muestra una continuidad sin cuellos de botella poblacionales en el sur de África (Kim et al. 2014). La práctica de compartir la carne obtenida de la caza de animales grandes parece ser una clave importante para mantener lazos sociales firmes.

\section{(II) Información paleoantropológica y «the incest prohibition»}

Las normas para la aceptación de matrimonios y la prohibición del incesto suponen la existencia previa de todas las capacidades cognitivas que caracterizan a las poblaciones humanas actuales. Las capacidades cognitivas y la forma del cerebro están íntimamente relacionadas. Los humanos anatómicamente modernos tenemos cerebros de forma globular junto a rostros pequeños y retraídos (Neubauer et al. 2018).

Restos fósiles de homínidos encontrados en 1961 y 1962 en Jebel Irhoud (en Marruecos, noroeste de África), con algunos rasgos morfológicos característicos de humanos anatómicamente modernos (Hublin et al. 2017), fueron fechados recientemente en $315 \pm 34$ ka (Ritcher et al. 2017). Estos restos constituyen evidencia de una fase temprana en la evolución del linaje humano moderno.

Dado que tanto el tamaño como la forma del cerebro evolucionaron de forma independiente y en paralelo a lo largo de los linajes humanos Neandertales y anatómicamente modernos durante al menos 400 mil años, diferencias cognitivas pudieron haberse desarrollado entre las dos especies durante ese tiempo (Stringer \& Galway-Witham 2017).

Las diferencias anatómicas entre los cráneos de Neandertales y de humanos anatómicamente modernos permiten suponer el surgimiento de capacidades sociales y de aprendizaje exclusivas de nuestra especie (Bastir et al. 2011). Los humanos anatómicamente modernos tienen hemisferios cerebelosos relativamente más grandes, que están relacionados con funciones cognitivas y sociales superiores, incluido el procesamiento del lenguaje, la capacidad de producir y comprender sonidos y signos, lo que permite la comunicación compartida entre individuos (Kochiyama et al. 2018), necesaria para la constitución de grupos humanos estructurados bajo relaciones de parentesco. 


\section{(III) Información genética $y$ «the transition»}

El ADN mitocondrial se transmite por vía materna sin recombinación, acumulando cambios lentamente durante generaciones y determinando la variabilidad de los mitogenomas. Todos los mitogenomas humanos conocidos se derivan del mitogenoma de un ancestro femenino que vivió hace miles de años. La población a la que perteneció ese ancestro es la población ancestral. Los cálculos que utilizan el ADN mitocondrial como un reloj molecular estiman cuándo vivió ese ancestro femenino (Kivisild 2015).

El primer uso del ADN mitocondrial humano como reloj molecular estimó nuestro origen 200 ka atrás en África (Cann et al. 1987). Un estudio reciente también estimó que el ancestro común más reciente vivió 200 ka atrás en África (Chan et al. 2019).

Diferentes datos paleoclimáticos tomados en cuenta por los autores de esta última investigación, les permitieron sugerir que la región donde habitaba la población ancestral, población a la que pertenecía el ancestro femenino, era un humedal ubicado en una región ahora árida de la meseta de Kalahari, en el sur de África (en Botswana). El linaje L0 habría surgido en el entorno del paleohumedal Makgadikgadi-Okavango del sur de África, 200 ka atrás (Chan et al. 2019).

Este paleohumedal rodeado de pastizales y bosques, que ha sido propuesto como antiguo refugio de varios herbívoros, entre ellos una cebra -Equus quagga- ampliamente distribuida ahora en las sabanas africanas (Pedersen et al. 2018), podría haber reunido condiciones muy favorables para la supervivencia de grupos de cazadores-recolectores, funcionando también como refugio para una población humana.

Los investigadores tienden a considerar que el tiempo del ancestro común más reciente de todos los linajes mitocondriales conocidos de las poblaciones humanas actuales podría señalar un cuello de botella poblacional. Pero podría significar el comienzo del predominio en África de unas poblaciones humanas sobre otras, ahora desaparecidas y desconocidas.

\section{LA TEORIA}

Una falange humana hallada en 2010 en la cueva Denisova, montañas Altai (en Siberia), corresponde a una mujer Neandertal. El estudio de su genoma nuclear reveló un coeficiente de endogamia de 1/8, lo que indica que sus padres eran medios hermanos que tenían una madre en común, primos hermanos dobles, un tío y un sobrina, tía y sobrino, abuelo y nieta, o abuela y nieto (Prüfer et al. 2014). De forma provisional, el genoma de esta Neandertal permite sugerir la ausencia de normas para la formación de matrimonios entre Neandertales, a diferencia de las sociedades cazadoras-recolectoras actuales. De acuerdo a la endogamia registrada y la información paleoantropológica recién comentada, el surgimiento de normas para la formación de matrimonios que caracterizan a las sociedades humanas de nuestro linaje podría ubicarse luego de la separación con el linaje que daría lugar a los Neandertales, como resultado del desarrollo de nuevas capacidades cognitivas.

Aún se desconoce cuándo se ensamblaron las distintas capacidades cognitivas para conformar sociedades de cazadores-recolectores tan complejas como las conocidas etnográficamente. Sugiero que las relaciones de 
parentesco y las normas para la formación de matrimonios, con extensas redes de relaciones recíprocas que favorecen la supervivencia, ya estaban establecidas en grupos humanos portadores del haplogrupo mitocondrial L0, 200 ka atrás en el sur de África. Las poblaciones derivadas de esa población ancestral transmitieron, en paralelo a los mitogenomas, las nuevas y más complejas formas de vida. Los resultados de los estudios genéticos, en los que se puede estimar la consanguinidad en restos humanos de África, podrán probar esta suposición.

Todavía no hay evidencia firme de que los grupos humanos antiguos estuvieran relacionados socialmente, 200 ka atrás, como lo hicieron las familias Ju/'hoansi durante los años cincuenta, pero no hay argumentos firmes para descartar la existencia de relaciones sociales similares hace tanto tiempo.

Las relaciones de parentesco y normas para la formación de matrimonios pudieron surgir en un pasado remoto junto a redes de relaciones de reciprocidad extensas que facilitaron la distribución de la carne obtenida mediante la caza de grandes animales y que favorecieron la supervivencia grupal. Las capacidades cognitivas de los humanos modernos pudieron expresarse, en el pasado, en la preocupación por fortalecer los lazos sociales y no necesariamente en la producción de artefactos que permitan hoy a los arqueólogos reconocer estas capacidades, generando brechas de tiempo entre unas y otras expresiones.

\section{CONSIDERACIONES ADICIONALES}

Sugiero que la configuración de nuevos y más complejos lazos sociales en una población humana ancestral, más exitosa en términos de supervivencia, marcó el inicio de un modo de vida que terminaría con el predominio de ese linaje humano sobre otros linajes homínidos en los que aquellos lazos no existían. Desde esta perspectiva, la configuración de nuevas redes de relaciones recíprocas favoreció la supervivencia de grupos modernos de cazadores-recolectores que se encontraban dispersos por casi todo el planeta, actualizando un modelo fuera de África (Scerri et al. 2019), que ahora incluye una componente social nunca antes, de acuerdo a mi conocimiento, tenido en cuenta. En los humanos anatómicamente modernos dispersos por el planeta pudieron existir límites para la aceptación de matrimonios fuera del espacio social donde se expresan las redes de relaciones sociales, considerando a Neandertales y a otros homínidos como extraños. El limitado flujo de genes que se produjo entre humanos anatómicamente modernos y otros linajes de homínidos (Pääbo 2015) no descarta esta posibilidad.

Según diferentes evidencias, en particular la recuperación de herramientas de caza en el sitio arqueológico de Schöningen (en Alemania) (Conard et al. 2020), se considera que las habilidades para la caza de animales fueron compartidas por varios linajes humanos. En nuestro linaje, el ensayo de nuevos modos de caza y el surgimiento de nuevas tecnologías relacionadas con la caza, como el uso de arcos y flechas, podrían verse como la expresión de habilidades cognitivas modernas ligadas a la importancia otorgada a la caza de animales de gran tamaño.

La insistencia en la caza de animales de gran tamaño por parte de grupos humanos que se han dispersado por el planeta durante los últimos 50 mil años (Martin 2005), podría ser un indicador de una forma de vida similar a la que conocemos de los grupos cazadores-recolectores del siglo veinte. La importancia otorgada a 
la caza de animales de gran tamaño, podría haber sido una motivación importante para la exploración de nuevos paisajes habitados por animales más vulnerables a nuevos y desconocidos predadores humanos (Tucci \& Akey 2016).

\section{Desaparición de Neandertales}

Dos molares deciduos de 45-43 ka atrás de Grotta del Cavallo (en Italia), dan cuenta de la presencia temprana de humanos anatómicamente modernos en Europa (Benazzi et al. 2011). El complejo tecnológico asociado con estos restos humanos incluye conjuntos líticos, adornos personales en forma de cuentas de conchas marinas, hueso trabajado y colorantes. El análisis sistemático de huellas de uso de 146 piezas líticas indica que la función principal de estas piezas era la caza, formando parte de proyectiles impulsados mecanicamente (Sano et al. 2019).

El reemplazo de Neandertales por humanos anatómicamente modernos, 40 ka atrás, es bien conocida por la buena conservación de restos orgánicos que permitieron recuperar ADN antiguo para estudios genéticos y otros restos orgánicos para dataciones radiocarbónicas. La coexistencia de humanos anatómicamente modernos y Neandertales pudo estimarse en 2.6-5.4 mil años (Higham et al. 2014; Douka 2019). Procesos de reemplazo de otros linajes de Homo ocurrieron en otras regiones del planeta.

\section{La ocupación de Siberia}

Un fémur humano hallado en 2008, a orillas del río Irtysh, cerca del asentamiento de Ust'-Ishim, (oeste de Siberia), corresponde a un individuo anatómicamente moderno. Este cazador vivió $\sim 45$ ka atrás, probablemente durante un período cálido propuesto como una época de expansión de humanos modernos en Europa (Fu et al. 2014). Según el estudio de su genoma nuclear, no hay evidencia de endogamia reciente entre los ancestros de este individuo (Fu et al. 2014).

Además de las condiciones climáticas que pudieron haber favorecido la expansión de grupos de cazadoresrecolectores hacia latitudes frías, los ancestros de este cazador pudieron haber explorado la región atraídos por la presencia de animales de gran tamaño. Pudieron haber contribuido a la extinción de Elasmotherium, un rinoceronte de 3.5 toneladas de peso (Kosintsev et al. 2019), aunque sus restos no se han encontrado aún en contextos arqueológicos.

\section{La ocupación de Sahul}

Sahul, una masa de tierra única formada por la unión de Australia y Nueva Guinea, fue la primera gran masa de tierra nunca ocupada por homínidos a la que llegaron humanos anatómicamente modernos. Se recolectaron cientos de fragmentos de cáscara de huevo en dunas de arena recientemente erosionadas de diferentes regiones de Australia, fuera de cualquier contexto arqueológico obvio. Muchos de estos fragmentos tienen los extremos ennegrecidos debido a su exposición a altas temperaturas, probablemente por haber sido cocinados en fogones efímeros siguiendo el mismo método utilizado por los aborígenes australianos en tiempos históricos: cocción relativamente lenta de huevos envueltos en vegetales o enterrados 
en cenizas calientes (Miller et al. 2016). Los fragmentos quemados más antiguos tienen una antigüedad de 53.9 ka y señalan el comienzo de una presencia continua de cazadores hasta tiempos recientes (Miller et al. 2016).

El sitio arqueológico Warratyi, recientemente excavado, se encuentra en una de las regiones más áridas de Australia, estuvo habitado desde $\sim 49$ ka atrás por grupos de cazadores-recolectores que coexistieron con fauna extinta (Hamm et al. 2016). Un hueso descubierto en una de las capas más antiguas del alero pertenece a Diprotodon, el mayor de los mamíferos marsupiales de Sahul, un herbívoro de más de 2 toneladas de peso que probablemente fue cazado y consumido en ese lugar (Hamm et al. 2016). En Australia, las extinciones afectaron afectaron a todos los animales por encima de los 45 kilogramos de peso, mientras que mamíferos mucho más grandes lograron sobrevivir en Europa y en las Américas (Johnson 2006).

Dos estudios genéticos recientes confirman el asentamiento inicial de Sahul 50 ka atrás (Nagle et al. 2017; Tobler et al. 2017). Uno de estos estudios, que incluye el análisis de mitogenomas de muestras de cabello de 111 aborígenes, indica que el asentamiento inicial fue seguido por una rápida migración a lo largo de la costa este y oeste que llegó al sur de Australia 49-45 ka atrás (Tobler et al. 2017). Los investigadores encontraron evidencia de la presencia continua de poblaciones humanas en áreas geográficas discretas. Los patrones filogeográficos diversos y de larga data documentados son notables dada la escala de tiempo involucrada, y plantean la posibilidad de que el vínculo cultural central de los aborígenes australianos con el territorio pueda reflejar la presencia continua de poblaciones en áreas geográficas discretas durante 50 mil años (Tobler et al. 2017).

\section{CONCLUSIONES}

El sitio arqueológico Pinnacle Point, una cueva en la costa sur de África (Marean et al. 2007), proporciona fuertes evidencias de que los humanos que la habitaron mostraron elementos clave de los comportamientos modernos desde 165 ka atrás (McBrearty et al. 2007). Algunos investigadores creen que la capacidad cognitiva moderna surgió al mismo tiempo que la anatomía moderna, 200 ka atrás, y que varios aspectos de la cultura humana surgieron gradualmente a lo largo de los siguientes milenios, dando forma a un conjunto de comportamientos humanos modernos en África (McBrearty et al. 2007).

La formación de redes de parentesco y normas para la aceptación de matrimonios en torno a la prohibición del incesto es universal en las sociedades cazadoras-recolectoras de hoy. (Lévi-Strauss 1969 [1949]). Creo que algunos estudios recientes, especialmente genéticos, brindan pistas importantes para ubicar los inicios de sociedades cazadoras-recolectoras tan complejas como las conocidas etnográficamente. Sugiero que estas sociedades ya se establecieron 200 ka atrás en el sur de África.

En este sentido, creo que la información etnográfica puede ser tenida en cuenta para la interpretación de procesos sociales ocurridos en el pasado remoto. Los lazos sociales bien establecidos permitieron que varios grupos Ju/’hoansi compartieran un pozo de agua durante una estación particularmente seca en la sabana árida en los años cincuenta. Los mismos lazos sociales pudieron permitir compartir, entre varios grupos de cazadores, la carne de un animal de gran tamaño cazado recientemente, como un rinoceronte gigante, en la 
fría estepa ártica.

\section{BIBLIOGRAPHY}

Bastir M, Rosas A, Gunz P, et al (2011) Evolution of the base of the brain in highly encephalized human species. Nature Communications 2:588

Benazzi S, Douka K, Fornai C, et al (2011) Early dispersal of modern humans in Europe and implications for Neanderthal behaviour. Nature 479:525-528

Cann R, Stoneking M, Wilson A, et al (1987) Mitochondrial DNA and human evolution. Nature 325:31-36

Chan E, Timmermann A, Baldi B, et al (2019) Human origins in a southern African palaeo-wetland and first migrations. Nature 575:185-189

Conard NJ, Serangeli J, Bigga G, et al (2020) A 300,000-year-old throwing stick from Schöningen, northern Germany, documents the evolution of human hunting. Nature Ecology \& Evolution 4:690-693

Douka K (2019) No hard borders for humans. Nature Ecology \& Evolution 3:157-158

Fu Q, Li H, Moorjani P, et al (2014) Genome sequence of a 45,000-year-old modern human from western Siberia. Nature 514:445-450

Hamm G, Mitchell P, Arnold LJ, et al (2016) Cultural innovation and megafauna interaction in the early settlement of arid Australia. Nature 539:280-283

Higham T, Douka K, Wood R, et al (2014) The timing and spatiotemporal patterning of Neanderthal disappearance. Nature 512:306-309

Hublin J-J, Ben-Ncer A, Bailey S, et al (2017) New fossils from Jebel Irhoud, Morocco and the pan- African origin of Homo sapiens. Nature 546:289-292

Johnson C (2006) Australia’s mammal extinctions: a 50,000 year history, Cambridge University Press, New York

Kim HL, Ratan A, Perry GH, et al (2014) Khoisan hunter-gatherers have been the largest population throughout most of modern-human demographic history. Nature Communications 5:5692

Kivisild T (2015) Maternal ancestry and population history from whole mitochondrial genomes. Investigative Genetics 6:3

Kochiyama T, Ogihara N, Tanabe HC, et al (2018) Reconstructing the Neanderthal brain using computational anatomy. Nature Scientific Reports 8:6296

Kosintsev P, Mitchell KJ, Devièse T, et al (2019) Evolution and extinction of the giant rhinoceros Elasmotherium sibiricum sheds light on late Quaternary megafaunal extinctions. Nature Ecology \& Evolution 3:31-38

Kuper A (2009) Claude Lévi-Strauss (1908-2009). Nature 562:862

Lee RB, DeVore I (1976) Kalahari Hunter-Gatherers. Studies of the !Kung San and The Neighbors, Harvard University Press, Cambridge, Massachusetts and London 
Leví-Strauss C (1969) The Elementary Structures of Kinship, Bell JH, Von Sturmer JR (tr), Needham R (ed), Eyre \& Spottiswoode, London [Leví-Strauss C (1949) Les structures élémentaires de la parenté, Presses Universitaires de France, Paris]

Marean CW, Bar-Matthews M, Bernatchez J, et al (2007) Early human use of marine resources and pigment in South Africa during the Middle Pleistocene. Nature 449:905-908

Marshall L (1976) The !Kung of Nyae Nyae, Harvard University Press, Cambridge

Martin P (2005) Twilight of the mammoths: ice age extinctions and the rewilding of America, University of California Press, Berkeley and Los Angeles

McBrearty S, Stringer C (2007) The coast in colour. Nature 449:793-794

Miller G, Magee J, Smith M, et al (2016) Human predation contributed to the extinction of the Australian megafaunal bird Genyornis newtoni $\sim 47$ ka. Nature Communications 7:10496

Nagle N, van Oven M, Wilcox S, et al (2017) Aboriginal Australian mitochondrial genome variation - an increased understanding of population antiquity and diversity. Nature Scientific Reports 7:43041

Neubauer S, Hublin J-J, Gunz P (2018) The evolution of modern human brain shape. Science Advances 4:eaao5961

Pääbo S (2015) The diverse origins of the human gene pool. Nature 16:313-314

Pedersen C-E, Albrechtsen A, Etter P, et al (2018) A southern African origin and cryptic structure in the highly mobile plains zebra. Nature 2:491-498

Prüfer K, Racimo F, Patterson N, et al (2014) The complete genome sequence of a Neanderthal from the Altai Mountains. Nature 505:43-49

Ritcher D, Grün R, Joannes-Boyau R, et al (2017) The age of the hominin fossils from Jebel Irhoud, Morocco, and the origins of the Middle Stone Age. Nature 546:293-296

Sano K, Arrighi S, Stani C, et al (2019) The earliest evidence for mechanically delivered projectile weapons in Europe. Nature 3:1409-1414

Scerri E, Chikhi L, Thomas M (2019) Beyond multiregional and simple out-of-Africa models of human evolution. Nature 3:1370-1372

Stringer C, Galway-Witham J (2017) On the origin of our species. Nature 546:212-214

Tobler R, Rohrlach A, Soubrier J, et al (2017) Aboriginal mitogenomes reveal 50,000 years of regionalism in Australia. Nature 544:180-184

Tucci S, Akey J (2016) A map of human wanderlust. Nature 538:179-180 